\title{
The effect of temperature and time of extraction on the quality of Semi Refined Carrageenan (SRC)
}

\author{
Heri Heriyanto ${ }^{*}$ Indar Kustiningsih, and Denni Kartika Sari \\ Departemen of Chemical Engineering University of Sultan Ageng Tirtayasa, Indonesian, Jln Jenderal Sudirman Km 3, Cilegon, Indonesia
}

\begin{abstract}
Euchema cottonii is a good source of kappa-carrageenan and can be found cultivated in the Indonesia coastal areas in which one of them is in Banten Province. Carrageenans have many applications and are utilized in human food and pet-food industry. Carrageenans are also utilized in non-food industry such as pharmaceuticals, cosmetics, printing and textile formulations. Hence, the present study features on the cooking process cooking time and cooking temperature. The effects of these parameters on carrageenan quality such as gel viscosity and gel strength were studied. The process of extraction of carrageenan was conducted with variations temperature: 60,70 , and $80^{\circ} \mathrm{C}$ and the variation of time: 1,2 , and 3 hours. Alkaline substance used was $\mathrm{KOH}$ with $8 \%$ concentration and the ratio of solvent to dry seaweed $8: 1$. From the present investigation, it was observed that SRC extraction reached the best condition at temperature $70{ }^{\circ} \mathrm{C}$ for 2 hours with the value of yield $30.20 \%$, 5.90\% moisture content, $18.34 \%$ ash content, sulfate content of $6.94 \%$, viscosity of $190 \mathrm{cP}$, and the gel strength $714.45 \mathrm{~g} / \mathrm{cm}^{2}$. The treatment of temperature and extraction time significantly affected the quality of the SRC yield parameter, viscosity and gel strength.

Keywords: Eucheuma cottonii, Semi Refined Carrageenan (SRC), Time, Temperature
\end{abstract}

\section{Introduction}

Carrageenan is the sulfated product form of Dgalactan obtained from different species of marine red alge (Zhu et.al, 2017). Then this type are taxonomically called Kappaphycus alvarezii. Seaweeds represent a natural resource of numerous valuable compounds such as polyphenols, vitamins, peptides and polysaccharides (Yousuf et.al, 2017). Some types of Euchema have an important role in the world of international trade as a producer of carrageenan extracts. Carrageenan levels within each species Euchema ranges from 54-73\% depending on the type and location of the growth. The Southeast Asian countries have produced $96.5 \%$ of the total production of k-carrageenan extracted from red seaweed; of which $55 \%$ is contributed by Philippines, followed by Indonesia (38\%) and Malaysia (2.5\%) (Awang, et al, 2012)

Carrageenan is an alternating copolymer of $\alpha(1-3)-\mathrm{D}-$ galactose and $\beta(1-4)-3,6-$ anhydro-D-galactose and is classified as kappa ( $\kappa)$, iota (i), and lambda $(\lambda)$ based on the number of sulfate ester groups and presence of 3,6anhydro-D-galacto. Among the polysaccharides, carrageenans have attracted intense attention due to its wide range of applications in food industry, such as thickening, gelling, stabilising agents and binder for the manufacture of different kinds of foods. Carrageenan consists of hydrocolloid compounds comprising ester potassium, sodium, magnesium and calcium sulfate. Carrageenan is a large molecules consisting of over 1,000 galactose residues, therefore carrageenan has a lot of variety (Balqis et al, 2017). In medicine Red seaweeds have also yielded a number of sulfated polysaccharides with potent anticoagulant activities (Jiao et al, 2011). Eucheuma cottonii or kappahycus alvarezi is good source of kappa carrageenan and it mainly harvested in Indonesia. The main component of Eucheuma cottonii is kappa carrageenan (Arif, 2014; Moses, 2015).

Banten had potential value for development of the Kappa Carrageenan to increase incomes value in banten province, especially for people who is living in the coast area as a center seaweed grass production. It can be seen from Kim (2015) area effectiv for seaweed growth in banten coast is about 907 ha. In effort to improve the economic value of seaweed made into the Semi Refined Carrageenan (SRC), that required a process to produce the SRC that meet the quality standards of food (food grade). Seaweed extraction process may affect the quality of the obtaining SRC. To get a quality that meets the standards of food SRC, research will be conduct on the temperature and time of extraction to know what is effect diffrent temprature to the quality of semi refned carrageenan. However, there are limited efforts to develop the optimization of process parameters in alkaline treatment. Hence, the present study emphasized on the production of SRC by alkaline treatment where the process parameters such as cooking temperature and cooking time would be investigated. The rheological properties of $\mathrm{k}$-carrageenan (K. alvarezii species); gel strength and viscosity were studied to determine the best condition for the alkaline treatment.

\footnotetext{
*Corresponding author: heri.heriyanto@untirta.ac.id
} 


\section{Experimental}

Raw seaweed was prepared using sun drying by fresh seaweed collected from farm. The first phase started with cleaning the seaweed which will be extracted to eliminate the salt, sand and undesirable seaweed. Carrageenan extraction process carried out at varied temperatures of 60,70 and $80 \mathrm{oC}$. The extraction time was also varied during 1,2, and 3 hours by using water as a solvent. Alkaline substance was used $\mathrm{KOH}$ with a concentration of $8 \%$, which mixed with water as a solvent in the extraction process with the ratio of solvent and dried seaweed 8: 1. Results of the extraction process was filtered and neutralized to $\mathrm{pH} 7-8$ with demin water. Then carrageenan neutralized, cutted and dried in the sun for 23 days before being made into carrageenan flour with disk mill.

\subsection{Materials and Method}

Seaweed Eucheuma cottonii was purchased from lontar, $\mathrm{KOH} 8 \%(\mathrm{w} / \mathrm{v})$ (Sigma Alderich), Water, pH paper aluminum foil

\subsection{Research Variables}

Fixed variables in this research were seaweed mass 100 gr, Volume KOH: 8\% (w / v), Comparison of the mass of seaweed and water: 1: $8(\mathrm{w} / \mathrm{v})$. Changed Variables in this research were Extraction temperature: $60 \mathrm{oC}, 70 \mathrm{oC}$ and $80 \mathrm{oC}$ and Extraction time: 1 hour, 2 hours, and 3 hours

\subsection{Characterisation}

\subsubsection{Ash content}

Carrageenan approximately 2 grams was put in a porcelain cup (B) which was known the dry weight, then being ashed in a furnace at a temperature of $550^{\circ} \mathrm{C}$ until free from ash. Further, the sample was being cooled in a desiccator and weighed as the final weight (A).

\subsubsection{Gel strength}

Sample was prepared by dissolving $1.5 \mathrm{~g}$ of SRC powder to $100 \mathrm{~mL}$ of distilled water with continuous magnetic stirring at $90^{\circ} \mathrm{C}$ around $20-30 \mathrm{~min}$. The sample was allowed to stabilize in a water bath to eliminate bubbles forms at $80-90^{\circ} \mathrm{C}$ for $15 \mathrm{~min}$. The viscous solution was poured into three $50 \mathrm{~mL}$ beakers and left for 20-30 min before sealing them. Samples were stored for $24 \mathrm{~h}$ and maintained at ambient temperature prior to analysis.

\subsubsection{Viscosity}

Sample of 7.5 gr was put into a $600 \mathrm{ml}$ beaker glass and then stirred using a magnetic stirrer. Then weigh as much as $492.5 \mathrm{~g}$ distilled water in a $600 \mathrm{ml}$ glass beaker, put the sample into a baker glass that already filled with distilled water. The solution was agitated for 10-15 minutes at room temperature, and heat to a temperature of $80^{\circ} \mathrm{C}$ and maintained for 10-15 minutes on a hot plate. Then remove and leave until the temperature $\pm 75 \mathrm{oC}$, measuring viscosity using spindle 2 at $30 \mathrm{rpm}$ spindle rpm and wait until stabilized (5-6 rounds).

\subsubsection{Calculation Sulfate Levels}

The sampel as much as $1 \mathrm{gr}$ was put into erlenmeyer flask by adding $0.2 \mathrm{~N} \mathrm{HCl} 50 \mathrm{ml}$ and reflux for 1 hour. Then add a $25 \mathrm{ml}$ solution of $10 \% \mathrm{H} 2 \mathrm{O} 2$, reflux forwarded to 5 hours. Then add $10 \mathrm{ml}$ of $10 \%$ Barium Chloride. Then heated in water bath for 2 hours. Then filtered using Whatman paper number 42 nd washed with boiling distilled water until it's free of chloride, then stir in a Whatman cup along Barium Sulfate precipitate in furnace temperature $1000 \mathrm{oC}$ until white. After that, weigh the cup and calculate the results.

\subsubsection{Spectophotometer FT-IR}

Before testing the sample with FT-IR spectophotometer, prepared solid samples ( $\mathrm{KBr}$ pellet manufacture) preceded by weighing 1-2 mg samples which free of water contained (preferably in freeze dry), then add 100-200 mg $\mathrm{KBr}$, wherein the ratio of $\mathrm{KBr}=1: 10$ subsequently crushed to powder. The sample mixture press in a vacuum at a pressed of 7-8 ton for 10-15 minutes to produce a transparent disk. Then input into Spectrophotometer FTIR instrument.

\section{Results and Discussion}

\subsection{Effect of Temperature and Time of Extraction of the Value of the Yield}

The yield was one of important parameter in assessing the effectiveness of process in making SRC. Yield calculation was performed to determine the percentage of SRC produced from dried seaweed which used based on the time and temperature of cooking. The Carrageenan yield testing results were shown in Figure 1

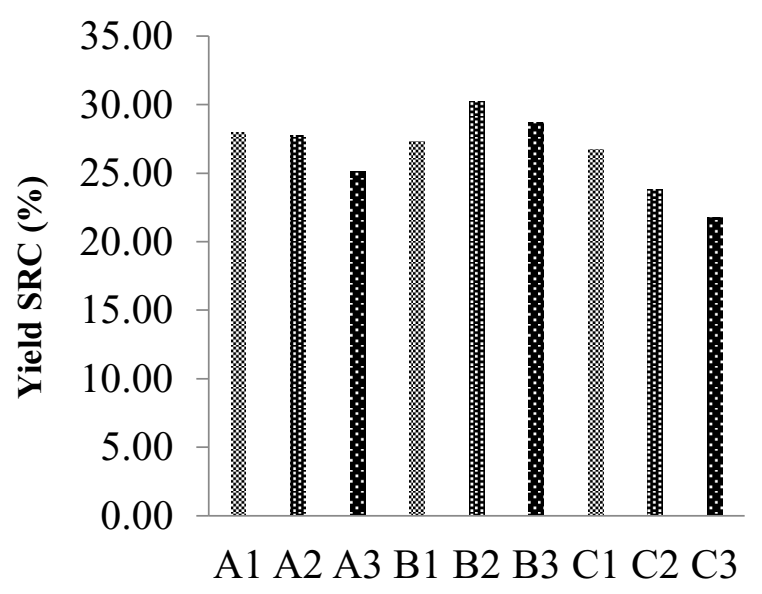

Fig.1. The test results SRC flour yield (\%) Vs 
Description: The difference in the letters $\mathrm{A}, \mathrm{B}$ and $\mathrm{C}$ showed the old extraction, $\mathrm{A}=1$ hour, $\mathrm{B}=2$ and $\mathrm{C}=3$ hours. Figures 1, 2 and 3 show the extraction temperature treatment, $1=60^{\circ} \mathrm{C}, 2=3=70^{\circ} \mathrm{C}$ and $80^{\circ} \mathrm{C}$.

Fig. 1 shows the yield of SRC's research ranges from $21.731 \%$ - 30.1979\%. The lowest yield was at the variation of 3 hours and temperature $80{ }^{\circ} \mathrm{C}(\mathrm{C} 3)$, where as the highest yield was in the variation time of 2 hours and a temperature of $70{ }^{0} \mathrm{C}$ (B2). The increase of temperatures will rise the melting point temperature of carrageenan, but will affect the carrageenan to come out from the talus and lowering the yield value. So the higher the temperature generated lower yield. Based on physical observations, the filtering process obtained more viscous alkaline solution at high temperature condition. This indicated a carrageenan which did not participate in the screening process filtered out and discarded. Time parameters as shown in Figure 1 has no effect on the temperature of $60^{\circ} \mathrm{C}$, but at a temperature of $70^{\circ} \mathrm{C}$ and $80^{\circ} \mathrm{C}$ time parameters affect the time of 2 hours into the optimum time to get a high yield that had the same result with Webber (2012) which increase temperature and extraction time affected in yield, the best result in our study were at $70{ }^{\circ} \mathrm{C}$ not at $80{ }^{\circ} \mathrm{C}$ that because At higher temperatures, biopolymer degradation may occur that the yield of carrageenan. The yield value increased because the longer extraction time will prolong sulfate binding process by alkaline materials.

\subsection{Effect of Temperature and Time of Extraction of the Value of Viscosity}

Viscosity was one of the physical properties of carrageenan which quite important. Tests were conducted to determine the viscosity of the carrageenan viscosity as a solution at a specific temperature and concentration. Here were the results of testing the viscosity analysis.

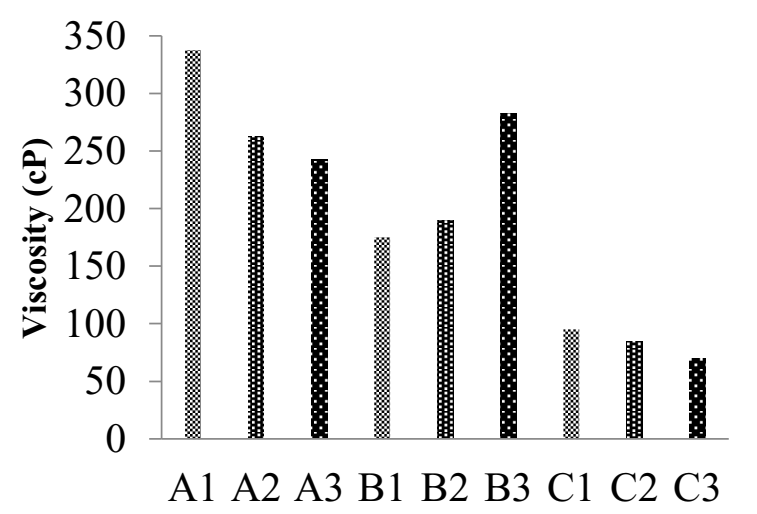

Fig.2. Viscosity (Cp)

Figure 2. showed that the viscosity of the analysis results still met FCC standards The highest values found in A1 which was treated with extraction time in 1 hour and $60{ }^{\circ} \mathrm{C}$, the value was $337.5 \mathrm{cP}$, and the lowest result in treatment $\mathrm{C} 3$ with the extraction time 3 hours at temperature $80^{\circ} \mathrm{C}$ which got value $70 \mathrm{cP}$. This confirmed that the time and temperature affected the viscosity values $\mathrm{SRC}$. The longer the extraction time will be longer the $\mathrm{K}^{+}$ ions in $\mathrm{KOH}$ bind sulfate groups resulting lower load the polymer chains so the electrostatic forces between the sulfate groups was reduced. According Velde and Ruiter (2002) due to the viscosity of the carrageenan caused by repulsive force in sulfate groups. It which had negative charge, which occur along whit polymer chain, causing the polymer chains were rigid and taut. Besides that their hydrophilic caused the molecules surrounded by the water not moving. The presence of water was not moving, as rising temperatures will cause the loss of the water and cause a decrease in viscosity. It has the simmiliar results that extraction done by Webber (2012) Carrageenan crude extract solution viscosity increased when the extraction temperature reached $60{ }^{\circ} \mathrm{C}$, and at higher temperatures this parameter decreased.

\subsection{Effect of Temperature and Time of Extraction of the Gel Strength Values}

Gel strength was the main physical properties of carrageenan, because the main function of flour SRC turned liquids into solids. Normah and nazarifah (2003) stated that one of the important physical properties of carrageenan was the power to form a gel called gel strength a kappa carrageenan gel was characterised as being strong, brittle and subject to syneresis. It was not freeze/thaw stable (Koliandris, 2009). The results of the study can be seen in Figure 3.

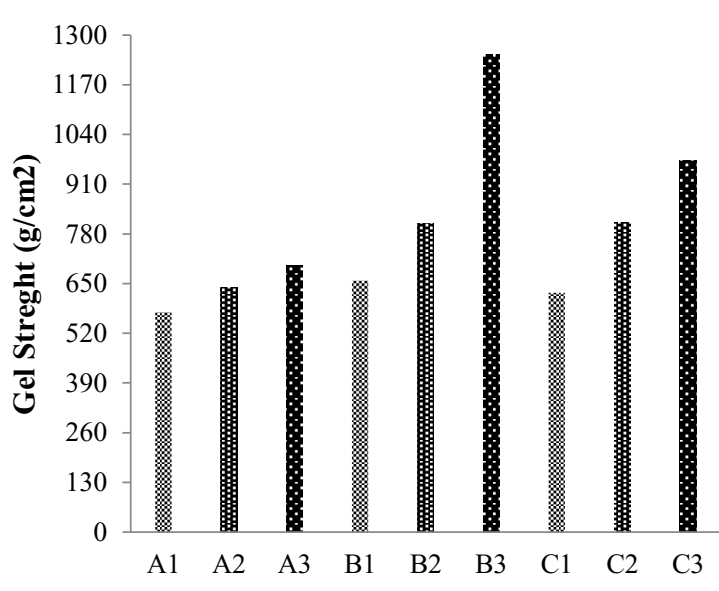

Figure 3. Gel Streght $\left(\mathrm{g} / \mathrm{cm}^{2}\right)$

Making SRC with C3 treatment at temperature of 80 ${ }^{\circ} \mathrm{C}$ for 2 hours obtained the highest gel strength value $1248.45 \mathrm{~g} / \mathrm{cm} 2$, while the lowest value was $574.45 \mathrm{~g} /$ $\mathrm{cm}^{2}$ with treatment $\mathrm{A} 1$ at $60^{\circ} \mathrm{C}$ for 1 hour. Gel strength values with a variety of treatments were still in accordance with the standards established FCC i.e $\geq 500$ $\mathrm{g} / \mathrm{cm}^{2}$.

Figure 3 explained that the higher temperature and duration of extraction will cause a rise in the value of the gel strength. Pathik (2006) Reported that Kappaphycus alvarezii, when heated in an alkaline solution of potassium hydroxide by increase the time of extraction will increase gel strength. The hydroxide part of the 
reagent penetrated the seaweed, reduced the amount of sulfate in the carrageenan and increasing the 3,6-AG, thereby improving the gel strength of the carrageenan. Polysaccharide gel was a 3-dimensional structure which was formed from polymer solution. The process of gel formation occurs because of the bonds between the polymer chains formed a three-dimensional structure which contained a solvent in its gaps. $\mathrm{K}+$ cations in the $\mathrm{KOH}$ can serve as a binder so the 3-dimensional structure of the polymer will maintain its shape when subjected to pressure (Peter, 1996; Velde and Ruiter, 2002). The rise in temperature and duration of the extraction will cause $\mathrm{K}^{+}$ions will be optimized to form a three-dimensional structure of the polymer.

\subsection{Effect of Temperature and Duration of Extraction of the Value Sulfate Content}

Sulfate content was one of the physical properties that were important to noted in the manufacturing of carrageenan. Kappa carrageenan corresponded to the less sulfated ideal polymer and leads to strong and elastic gels showing thermal hysteresis. In contrast to that, 1carrageenan corresponds to the more sulfated ideal structure which cannot form helices in solution and consequently did not exhibit gelling properties. The content of sulfate caused a repel force between negatively charged sulfate groups, so that the polymer chains got stiff and taut, causing an increase in viscosity (Manuhara, 2016). So that known why Sulfate content was directly proportional to viscosity values, where the higher levels of sulfates generate higher viscosity values obtained but inversely proportional to the value of the gel strength (Hilliou, 2006). The results of the study were shown in Figure 4.

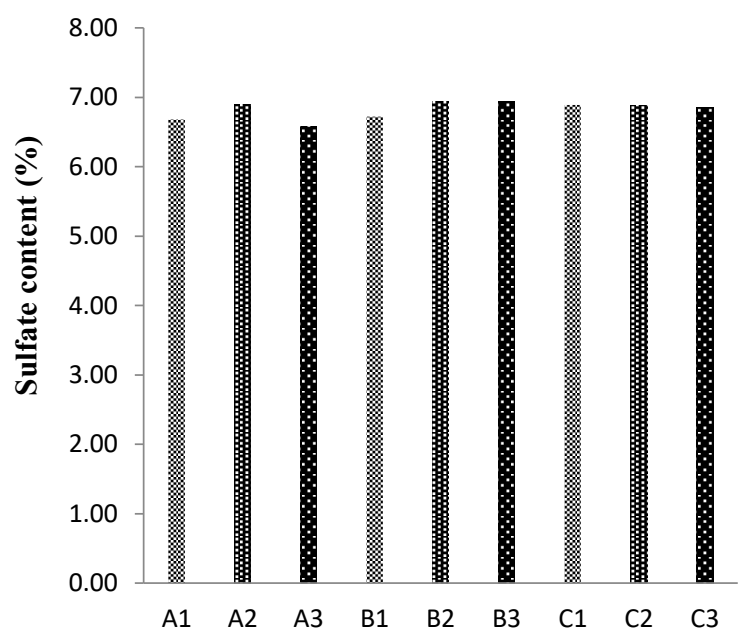

Fig.4. The Test Results SRC Sulfate Content (\%)

Figure 4 showed that the value of the highest sulfate content of $6.94 \%$ with 2 hours extraction treatment at temperature $80{ }^{\circ} \mathrm{C}$ and the lowest value of sulfate was when treatment temperature $80^{\circ} \mathrm{C}$ for 1 hour, it's about $6.58 \%$. Carrageenan can be distinguished by levels of sulfates into two fractions, namely kappa carrageenan containing sulfate less than $28 \%$ and iota carrageenan if it contained more than 30\% (Diharmi et al. 2017). Based on FCC standards, which met maximum quality of SRC was $40 \%$ sulfate content. According to Moses (2015) the KOH solution given during processing would reacted with sulfate groups in the carrageenan form K2SO4 salt and sulfuric acid. Sulfate content decreased with increasing concentration of $\mathrm{KOH}$ solution. So the magnitude of the temperature and the length of the extraction process did not affect the value of sulfate content.

\subsection{Effect of Temperature and Duration of Extraction of the Moisture Content}

One of the quality requirements of carrageenan was the value of carrageenan moisture content that generated a value of water content that has required both in trade and standards (FCC, 1981) which was semi-refined carrageenan product for a maximum of $12 \%$.

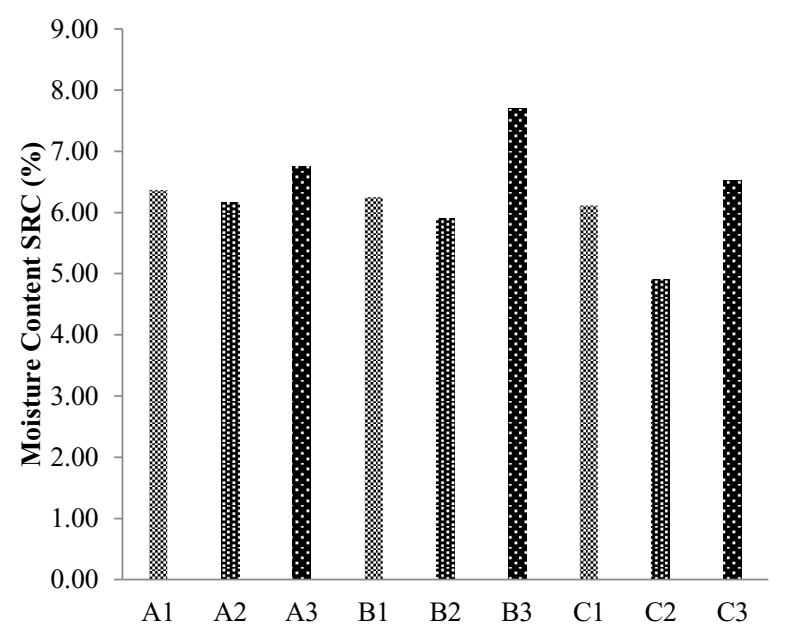

Fig.5. The Results Of The Analysis Of Flour SRC Moisture Content (\%)

The moisture content quality of SRC flour produced in this study shown in Figure 4.5. FCC standards set with maximum moisture content $12 \%$. The moisture content of all carrageenan samples met the FAO standard. The lowest value was $4.9097 \%$ in the samples $\mathrm{C} 2$ and the highest was $7.7038 \%$ in the sample B3. The size of the moisture content depended on the drying process. SRC drying process was done in the form of small pieces dried in a container with exposure to sunlight. The drying process was considered complete when the pieces SRC were already hard and easily broken (fragile). Drying process was not done using oven because it was feared product color scorched (brown). When it was used in the application will create a cloudy effect on product color. Drying factors by sunlight depended on the intensity of sunlight, humidity levels and wind speed.

\subsection{Effect of Temperature and Duration of Extraction of the Ash Content Value}

Standard specification of the required maximum ash content was 35\% (FCC, 1991). Basma et al. (2008) suggested that the ash content was strongly influenced by 
carrageenan processing techniques and the level of clean liness in the washing process of grass that has been extracted using alkali salt sea. The washing process was less clean can lead to excess $\mathrm{K}+$ ions on carrageenan, which would contribute to increased levels of ash. According to Ahmad (2005), potassium was a mineral element in the form of unburnt inorganic substances (ash).

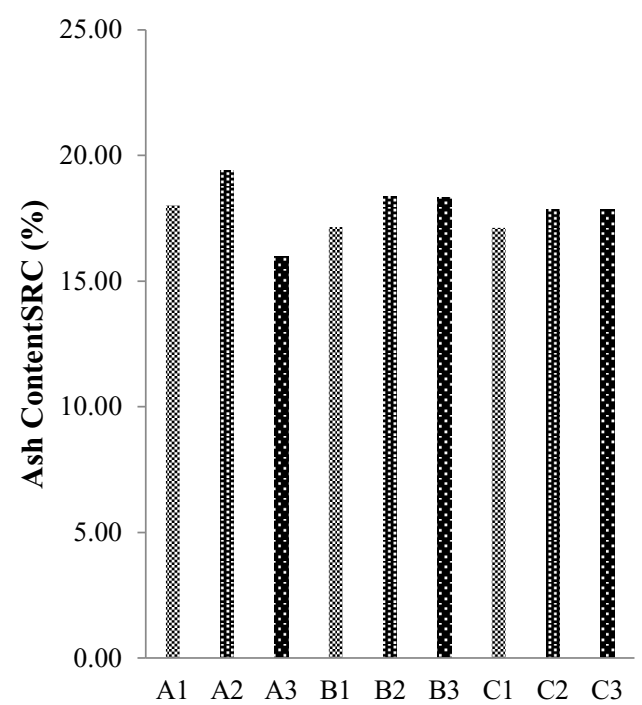

Fig.6. The Test Results SRC Ash Content (\%)

SRC ash content in flour product ranged from 15.9764 to $19.3919 \%$ are shown in Figure 6, it showed all carrageenan powder produced in this study meet the standards set by the FCC to the maximum limit ash content $35 \%$. The ash content product indicated the washing process of SRC after the extraction process had been carried out properly. The washing process was done by rinse SRC with water for $24 \mathrm{~L}$ or 6 times from the volume of alkali which being used. Washing was done until a minimum $\mathrm{pH}$ reached number 8 signifies that the $\mathrm{pH}$ was close to neutral so it could be assumed there was no excess of $\mathrm{K}+$ ions in the SRC.

\subsection{Characteristics of SRC Product Produced}

FTIR analysis was used to determine the presence of functional groups of molecules presented in a sample, where in the similarity of functional groups that existed between the standard and the sample state sample being analyzed was identical to the standard. Here was an FTIR spectrum of standard and samples that were generated, where both the spectrum comparable between groups function.

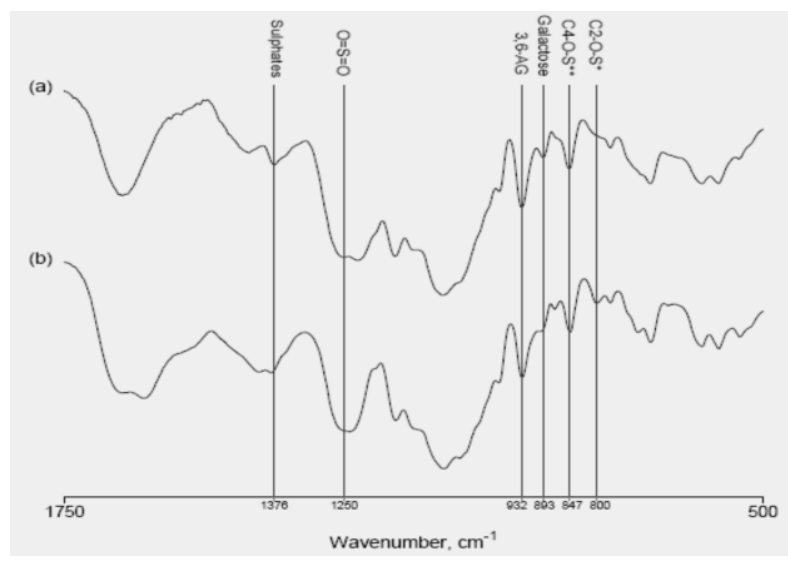

Fig.7. Standard FTIR Spectra Of Carrageenan (Mehta, 2008)

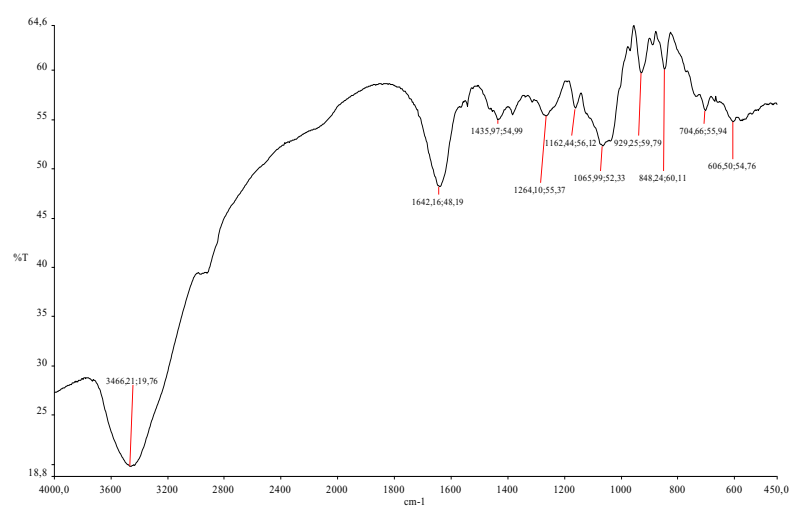

Fig.8. The FTIR Spectrum SRC Product Produced

In the spectra 1500-500 cm-1, FTIR spectroscopy showed a very strong beam absorption in the region 1162-1264 $\mathrm{cm}-1$ (for $\mathrm{S}=\mathrm{O}$ bond in the ester sulfate) and 848-1065 $\mathrm{cm}-1$ region (considered glycosidic bonds) on all kinds of carrageenan. From carrageenan product spectrum which had been obtained, known that using FTIR identification. The product met the specifications for a standard carrageenan functional groups contained in the resulting sample spectrum was identical to the standard spectrum of carrageenan. In the infrared spectrum of the compound carrageenan isolation results contained in Figure 4.8 looks a glycoside bond, 3,6-anhidro-D-galactose, D-galactose4-sulfate and 3,6-anhidro-D-galactose-2-sulfate ,

Below was the comparison of the characteristics of the SRC product produced to standards set by the FCC based on the optimum yield.

Table 1. Comparison of Product Characteristics SRC FCC

\begin{tabular}{|l|l|r|}
\hline \multicolumn{1}{|c|}{ Specification } & \multicolumn{1}{c|}{ FCC } & \multicolumn{1}{c|}{ Results } \\
\hline Sulfate (\%) & Maks 40 & 6.94 \\
\hline Viscosity (cP) & Min 5 & 190.00 \\
\hline Ash Content (\%) & Maks 35 & 18.36 \\
\hline Moisture Content (\%) & Maks 12 & 5.90 \\
\hline Gel Strengt $\left(\mathrm{g} / \mathrm{cm}^{2}\right)$ & $>500$ & 806.20 \\
\hline
\end{tabular}




\section{Conclusion}

Alkali treatment process conditions such as cooking temperature, cooking time were shown as important parameters for the production of semi refined carrageenan. The optimization of process parameters of alkaline treatmentwas developed in this study based on the characterization of carrageenan; gel strength,mousture content, sulfate content and viscosity. Semi Refined Carrageenan (SRC) of seaweed E.cottonii derived from Lontar (Banten) have been obtained with optimum extraction conditions at temperature $70{ }^{\circ} \mathrm{C}$ for 2 hours with yield of $30.20 \%, 5.90 \%$ moisture content, $18.34 \%$ ash content, sulfate content of $6.94 \%, 190 \mathrm{cP}$ viscosity and gel strength of $714.45 \mathrm{~g} / \mathrm{cm} 2$. The temperature and time of extraction influenced on the quality parameters of SRC produced at the yield, viscosity and gel strength.

This research was supported in part by IDB Islamic Development Bank

\section{References}

1. Ahmad Rafiq and Rizwana Jabeen. Pak. J. Bot., 37(4): 913-920 (2005)

2. Arif Nur Nabillah Bt Mohd. Chemical Engineering. Universiti Malaysia Pahang. Thesis (2014)

3. Bono Awang, Anisuzzaman 1 S.M., Ong Wan Ding. Engineering Sciences 26, 3-9 (2014)

4. Diharmi Andarini, Fardiaz Dedi, Nuri Andarwulan and Endang S. Heruwati, Phycological Research. 16., (2017)

5. Guiseley KB, Stanley NF, Whitehouse PA, 1980, Davids RL (editor), Hand Book of Water Soluble Gums and Resins, New York, Toronto, London: Mc Graw Hill Book Company

6. Hilliou a L. Larotonda , F.D.S., P. Abreu , A.M. Ramos , A.M. Sereno , M.P. Gonc,Alves, Biomolecular Engineering 23:201-208 (2006)
7. Jiao Guangling , Guangli Yu, Junzeng Zhang and H. Stephen Ewart, Mar. Drugs, 196-223, (2011)

8. Kim Se-Kwon. 2015. Seafood Science: Advances in Chemistry, Technology and Applications. pp 372. Korea.CRC Press

9. Koliandris, Andreas, Relationship between texture of gels and flavour release. University of Nottingham. Thesis, (2009)

10. Manuhara Godras Jati, Praseptiangga Danar, Rachmad Adi Riyanto. Aquatic Procedia 7 :106 111, (2016)

11. Mehta, Indian Journal of chemical technology vol. 15, (2008)

12. Moses, J., Anandhakumar, R. and M. Shanmugam, African Jurnal of Biotechnology 14(18) :1584-1589, (2015)

13. Normah O. and Nazarifah, I.. J. Trop. Agric. and Fd. Sc. 31(2): 207-213, (2003)

14. Velde van de and Ruiter G.A. de., Carrageenan.Germany: Wiley-VCH, (2002)

15. Webber Vanessa, Matos De Carvalho Sabrina, Paulo José Ogliari1, Leila Hayashi1, Pedro Luiz Manique Barreto. Ciênc. Tecnol. Aliment., Campinas, 32(4): 812-818, (2012)

16. Youssouf, Latufa., Lallemand, Laura., Giraud, Pierre., Soule, Faiza., Bhaw-Luximon, Archana., Meilhac, Olivier., D'Hellencourt, Christian ' Lef' ebvre., Jhurry, Dhanjay., and Couprie, Joel. Carbohydrate Polymers, 1:18, 2017

17. Zhu, Mingjin., Ge, Liming., Lyu, Yongbo., Zi,Yaxin., Li, Xinying., Li, Defu., and Mu, Changdao. Carbohydrate Polymers. 1:24 (2017) 